\title{
Network reconfiguration and loss allocation for distribution systems with distributed generation
}

DOI:

10.1109/TDC.2004.1432379

Link to publication record in Manchester Research Explorer

\section{Citation for published version (APA):}

De Oliveira, M. E., Ochoa, L. F., Padilha-Feltrin, A., \& Mantovani, J. R. S. (2004). Network reconfiguration and loss allocation for distribution systems with distributed generation. In 2004 IEEE/PES Transmission and Distribution Conference and Exposition: Latin America/2004 IEEE/PES Transm. Distrib. Conf. Expo. Latin Amer. (pp. 206-211) https://doi.org/10.1109/TDC.2004.1432379

\section{Published in:}

2004 IEEE/PES Transmission and Distribution Conference and Exposition: Latin America|2004 IEEE/PES Transm. Distrib. Conf. Expo. Latin Amer.

\section{Citing this paper}

Please note that where the full-text provided on Manchester Research Explorer is the Author Accepted Manuscript or Proof version this may differ from the final Published version. If citing, it is advised that you check and use the publisher's definitive version.

\section{General rights}

Copyright and moral rights for the publications made accessible in the Research Explorer are retained by the authors and/or other copyright owners and it is a condition of accessing publications that users recognise and abide by the legal requirements associated with these rights.

\section{Takedown policy}

If you believe that this document breaches copyright please refer to the University of Manchester's Takedown Procedures [http://man.ac.uk/04Y6Bo] or contact uml.scholarlycommunications@manchester.ac.uk providing relevant details, so we can investigate your claim.

\section{OPEN ACCESS}




\title{
Network Reconfiguration and Loss Allocation for Distribution Systems with Distributed Generation
}

\author{
M. E. de Oliveira, L. F. Ochoa, Student Member, IEEE, A. Padilha-Feltrin, Member, IEEE, \\ and J. R. S. Mantovani
}

\begin{abstract}
Distribution systems with distributed generation require new analysis methods since networks are not longer passive. Two of the main problems in this new scenario are the network reconfiguration and the loss allocation. This work presents a distribution systems graphic simulator, developed with reconfiguration functions and a special focus on loss allocation, both considering the presence of distributed generation. This simulator uses a fast and robust power flow algorithm based on the current summation backward-forward technique. Reconfiguration problem is solved through a heuristic methodology and the losses allocation function, based on the Zbus method, is presented as an attached result for each obtained configuration. Results are presented and discussed, remarking the easiness of analysis through the graphic simulator as an excellent tool for planning and operation engineers, and very useful for training.
\end{abstract}

Index Terms-- Distribution systems, network reconfiguration, loss allocation, distributed generation.

\section{INTRODUCTION}

$\mathrm{E}^{\mathrm{L}}$ LECTRIC utilities are in constant development in order to improve the quality of their product, i.e. the electric energy supplied to their customers, aimed at attending a ever more exigent market. In this way, overhead distribution systems are mainly configured in a radial manner targeted to make easy inherent factors of the system protection, such as coordination and attenuation of short circuit currents, diminishing equipment costs. Low flexibility and reliability in the operation of radial distribution networks make those systems be constructed with extra equipment as sectionalizing switches. By changing the state of the sectionalizing switches (open or close), which means reconfiguring the network, the operation quality of the network can be improved [1], [2].

Changes in the topology of a distribution system is mainly aimed at diminishing real power losses in the feeders, improving the consumers voltage profile, increasing reliability levels and eliminating and/or isolating faults in order to restore the power supply. Thus, sectionalizing switches are

The first author would like to thank the "scientist initiation program" $\mathrm{CNPq} / \mathrm{Pibic}$ for the financial support.

M. E. Oliveira (e-mail: escobar@dee.feis.unesp.br), L. F. Ochoa (e-mail: luis_ochoa@ieee.org), A. Padilha-Feltrin (e-mail: padilha@dee.feis.unesp.br) and J. R S. Mantovani (e-mail: mant@dee.feis.unesp.br) are with Universidade Estadual Paulista (UNESP), Ilha Solteira, SP, Brazil. used for fault isolation (protection) as well as for configuration management (reconfiguration).

In order to avoid the combinatorial explosion due to the reconfiguration analysis, in the last decade were proposed approximated heuristic algorithms that warrant a good or almost optimal solution. Those algorithms eliminate undesirable switching options, decreasing the problem size.

Nowadays, distribution systems are being impacted by the increasing insertion of distributed generators, which were regularly used in the transmission system. Hence, distributed generation became one of the relevant parameters in the evaluation of systems reconfiguration. Distributed generation may affect distribution networks operation in various ways, contributing to the fault current, causing voltage oscillations, increasing/decreasing losses, etc., i.e. causing noticeable impacts depending on its location.

An interesting issue related to distributed generation is the loss allocation problem, which becomes more important with the introduction of utilities competition. Attribution of losses for generators and loads is, currently, important due to the possibility of free consumers and generators in distribution networks. Particularly, when small generators (power ratio less than $20 \mathrm{MW}$ ) are connected in distribution networks some important issues, such as the loss responsibility, should be understood for both parties, electric utilities and distributed generators owners.

In this work, a distribution networks graphic simulator with reconfiguration and loss allocation functions, is presented. Reconfiguration problem is solved through a heuristic methodology that uses mainly the criterion of the maximum voltage drop allowed by the feeders, using a robust power flow algorithm based on the current summation backwardforward technique, considering distributed generation. Loss allocation function, presented in the simulator as an attached result for each obtained configuration, is based on the Zbus method. Results for a 3-feeder 16-bus distribution network, are presented and discussed.

\section{Distribution Networks GRAPHIC SIMUlator}

Due to the difficulty of distribution systems planning, since is an optimization problem, it is very important the development of tools for helping in the training of system operators or in the teaching of electric engineering students. 
Computational software, as presented in [1], that provide the user few numeric outputs, are suitable for specialized engineers and technicians, however they present great drawbacks for results visualization and analysis, moreover, they have no usefulness for training.

Various graphic simulators have appeared for transmission networks analysis and training, but only few have been developed for distribution networks. This work presents a distribution systems graphic simulator based on Visual Basic, for analyzing network reconfiguration and loss allocation in distribution systems with distributed generation.

\section{POWER Flow ALgORITHM}

In this section, the adopted power flow algorithm from [3] will be briefly described. In this approach, each node or line section in the network is numbered by a single index, and following the numbering sequence presented in [3].

Assuming the root node to be the slack node with known voltage magnitude and angle, the iterative algorithm to solve the radial system that consists of three steps, is as follows.

At iteration $k$ :

1. Nodal current calculation

$$
\bar{I}_{i}^{(k)}=\left(\bar{S}_{i} / \bar{V}_{i}\right)^{(k-1)^{*}}
$$

where

$$
\begin{array}{lll}
\bar{I}_{i} & : & \text { current injections at node } i . \\
\bar{S}_{i} & : & \text { complex power injection (loads) at node } i . \\
\overline{V_{i}} & : & \text { voltage at node } i .
\end{array}
$$

2. Backward sweep - section current calculation

Starting from the line section in the last layer and moving towards the root node, the current in line section $l$ is:

$$
\bar{J}_{l}^{(k)}=-\bar{I}_{j}^{(k)}+\sum_{m \in M} \bar{J}_{m}^{(k)}
$$

where

$$
\begin{aligned}
& \bar{J}_{l} \quad: \quad \text { current flow on line section } l \text {. } \\
& \text { M : set of line sections connected downstream to }
\end{aligned}
$$

3. Forward sweep - nodal voltage calculation

Starting from the first layer and moving towards the last layer, the voltage at node $j$ is:

$$
\bar{V}_{j}^{(k)}=\bar{V}_{i}^{(k)}-\bar{Z}_{l} \cdot \bar{J}_{l}^{(k)}
$$

where

$$
\bar{Z}_{l} \quad: \quad \text { line impedance of section } l .
$$

\section{Convergence criterion}

After these steps are executed in one iteration, the power mismatches at each node are calculated. If the real or imaginary part of any of the power mismatches is greater than a convergence criterion, steps 1,2 and 3 are repeated until convergence is achieved.

The initial voltage for all nodes should be equal to the root node voltage magnitude.

\section{Distribution Networks ReCONFIGURATION}

Distribution networks reconfiguration problem can be formulated as a non-linear programming problem with integer variables whose solution involves the selection, among all possible configurations, of that which presents the smaller losses and satisfies a set of constraints [1]. The problem can be formulated as follows:

Minimize

$$
R L_{k}=\sum_{l=1}^{N R} R_{l} \cdot\left|\bar{I}_{l}\right|^{2}
$$

Subject to

- radiality;

- voltage levels constraints;

- reliability constraints;

- load balancing between feeders constraints; and,

- integer and continuous variables.

Where,

$R L_{k} \quad$ : total real power losses for configuration $k$.

$R_{l} \quad: \quad$ conductor resistance of section $l$.

$\bar{I}_{l} \quad:$ complex current through section $l$.

NR : number of branches for configuration $k$.

In order to solve the reconfiguration problem, which is difficult to handle due to its combinatorial nature, plus the complexity of the mathematical formulation, it was developed a heuristic methodology [1], that includes constraints from (1) and presents a criterion for neglecting configurations that should not be considered. This criterion is based on the maximum voltage drop allowed in the feeders, thus promising configurations can be identified. Besides, promising configurations should present smaller losses respect to the others. Consequently, the search space will have good feasible solutions.

Due to the radiality constraint from (1) be difficult to represent mathematically, programming rules based on concepts of artificial intelligence and decision trees search [1], were used.

Implemented algorithm identifies, from the sets of closed and opened sectionalizing switches, the initial system configuration. This initial configuration will be in the $n_{0}$ level of the decision tree, and every set of configurations generated by closing each originally opened sectionalizing switch, will form another level. Thus, by closing the first sectionalizing switch it will be formed the level $n_{l}$ of the tree, with the set of configurations generated from the previous level configurations (in this case, from level $n_{0}$ ). When a second sectionalizing switch is closed, all previous levels configurations will be taken into account for switching, i.e. configurations of levels $n_{0}$ and $n_{l}$, in order to generate configurations for level $n_{2}$. Hence, this procedure will be performed until all opened sectionalizing switches from initial configuration are taken for switching.

In the decision tree, the number of levels will be equal to the number of sectionalizing switches present in the system. In 
each level will be attractive configurations that will stay active and will generate other configurations in the subsequent levels. Unattractive configurations will be neglected immediately, and will not generate other configurations, as shown in Fig. 1.

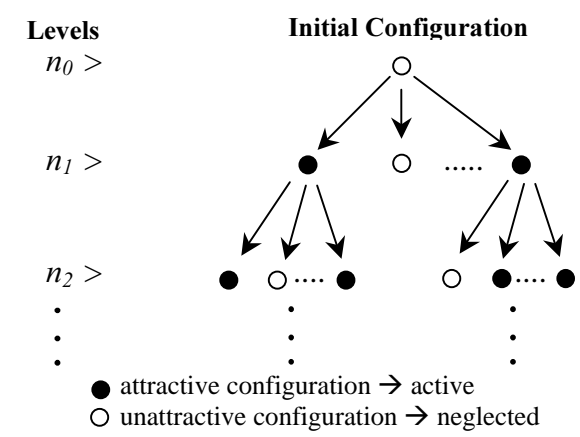

Fig. 1. Levels of the configurations tree (decision tree) [1].

In order to reduce the size of the configurations tree, it was established a method for examining only attractive configurations. Since voltage drop is directly related to the system losses, attractive configurations are selected based on the maximum voltage drop level, i.e. if the maximum voltage drop of some configuration exceeds a specified limit, the configuration will be considered as unattractive. Fig. 2 presents the flowchart of the developed algorithm for solving the reconfiguration problem.

For determining the voltage drop in the feeders, it was used in [1] an approximated power flow method. Although, this method was appropriate for its simplicity and quick response, it is not suitable for modeling distributed generation.

Nevertheless, the presented simulator was developed to consider the presence of distributed generation by using the power flow proposed in [3] (described in the previous section), capable of considering distributed generation.

\section{LOSS ALLOCATION}

Since last years distributed generation received more attention, loss allocation methods, traditionally used in transmission systems due to the great values of losses and the high number of consumers with free access to the system, are being applied in distribution networks.

Loss allocation in power systems shows the part of responsibility of each bus for its positive or negative influence in the total system losses.

Exigencies for an ideal loss allocation methodology may be resumed as follows [4]:

- Attribute to the consumer or generator the actual cost imposed to the system;

- Be consistent;

- Present bus incentives or penalties as a function of the location and magnitude of the power. Do not present a discriminatory behavior; and,

- Be simple for interpretation and implementation.

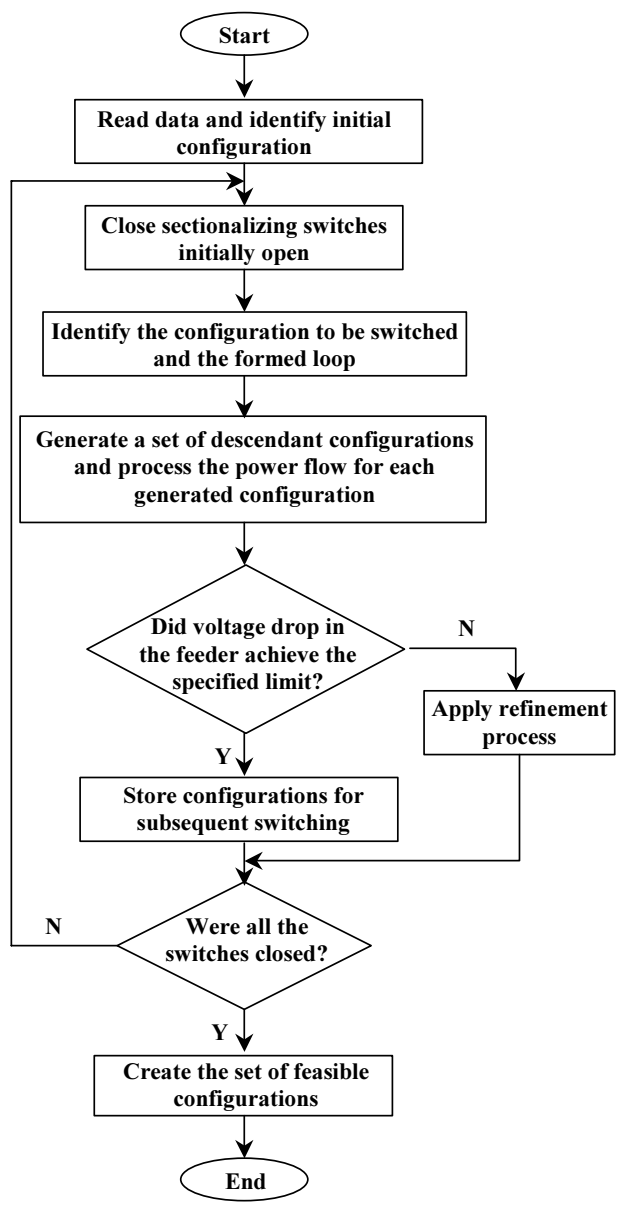

Fig. 2. Reconfiguration problem flowchart.

Due to the exposed exigencies and considering comparative studies performed in [4], this work will use the Zbus method for loss allocation.

\section{A. Zbus Method}

The idea for solving the loss allocation problem using Zbus matrix is to distribute transmission losses between the system buses [5]. This method can be developed from the complex power injection at bus $k$ :

$$
S_{k}=P_{k}+j Q_{k}=E_{k} I_{k}^{*}
$$

Where,

$P_{k} \quad: \quad$ real power injection at bus $k$.

$Q_{k} \quad:$ reactive power injection at bus $k$.

$E_{k} \quad: \quad$ complex voltage at bus $k$.

$I_{k}^{*} \quad:$ conjugated of the complex current injection at bus $k$.

Real power injection $P_{k}$ can be obtained with the following equation:

$$
\begin{gathered}
P_{k}=V_{k}^{2} G_{k k}+V_{k} \sum_{m \in \Omega_{k}} V_{m} G_{k m} \cos \theta_{k m}+ \\
V_{k} \sum_{m \in \Omega_{k}} V_{m} B_{k m} \operatorname{sen} \theta_{k m}
\end{gathered}
$$


Where,

$\Omega_{k} \quad: \quad$ set of nodes $m$, adjacent to bus $k$.

$V_{k} \quad: \quad$ voltage magnitude at bus $k$.

$G_{k m}:$ element $k m$ of conductance matrix.

$B_{k m} \quad: \quad$ element $k m$ of susceptance matrix.

$\theta_{k} \quad$ : voltage angle at bus $k$.

Equation (6) can be decomposed into two parts. First one $\left(L_{k}\right)$ is responsible for real power losses in each line connected to bus $k$, the second part is given by the summation of power flows (Flow) through each one of the lines connected to bus $k$, therefore this value will be zero (Kirchhoff's Current Law).

$$
\begin{gathered}
L_{k}=V_{k}^{2} G_{k k}+V_{k} \sum_{m \in \Omega_{k}} V_{m} G_{k m} \cos \theta_{k m} \\
\text { Flow }_{k}=V_{k} \sum_{m \in \Omega_{k}} V_{m} B_{k m} \operatorname{sen} \theta_{k m}
\end{gathered}
$$

Where,

$L_{k} \quad: \quad$ real power losses of lines connected to bus $k$.

Flow $_{k}$ : summation of power flows through each one of the lines connected to bus $k$.

Total real power losses $(L)$ of distribution networks can be expressed as a function of allocated losses at each bus from a set of $n$ buses.

$$
L=\sum_{k=1}^{n} L_{K}
$$

Since Flow $_{k}$ is equal to zero, total real power losses can be expressed as a function of $P_{k}$, as follows:

$$
L=\sum_{k=1}^{n} P_{K}
$$

Which can be re-written as:

$$
L=\Re\left\{\sum_{k=1}^{n} E_{k} I_{k}^{*}\right\}
$$

Since the current can be obtaining by:

$$
I_{k}=\sum_{j=1}^{n} Y_{k j} E_{j}
$$

Where,

$Y_{k j} \quad: \quad$ element $k j$ of admittance matrix.

Real power losses can also be expressed by the admittance matrix $(Y=G+j B)$ :

$$
L=\Re\left\{\sum_{k=1}^{n} E_{k}\left(\sum_{j=1}^{n} Y_{k j}^{*} E_{j}^{*}\right)\right\}
$$

Through the obtained admittance matrix, impedance matrix (Zbus) can be calculated:

$$
\text { Zbus }=Y^{\prime b u s}{ }^{-1}
$$

Thus, real power losses from (13) can be expressed from the system impedance matrix (Zbus).

$$
L=\Re\left\{\sum_{k=1}^{n} I_{k}^{*}\left(\sum_{j=1}^{n} Z_{k j} I_{j}\right)\right\}
$$

Where,

$$
Z_{k j} \quad: \quad \text { element } k j \text { of impedance matrix Zbus. }
$$

Separating (15), it is possible to obtain an expression with the sum of two terms. One term involves the resistance matrix, $R$, and the other involves the reactance matrix, $X$, as follows:

$$
\begin{aligned}
L= & \Re\left\{\sum_{k=1}^{n} I_{k}^{*}\left(\sum_{j=1}^{n} R_{k j} I_{j}\right)\right\}+ \\
& \Re\left\{\sum_{k=1}^{n} I_{k}^{*}\left(\sum_{j=1}^{n} X_{k j} I_{j}\right)\right\}
\end{aligned}
$$

Where,

$R_{k j} \quad: \quad$ element $k j$ of matrix $R$ (resistance part of Zbus)

$X_{k j} \quad$ : element $k j$ of matrix $X$ (reactance part of Zbus)

The second term of (16) represents the summation of power flows of buses connected through matrix Zbus to bus $k$. It can be proved that this summation is equal to zero, thus the first term of (16) represents the power system losses $(L)$ :

$$
L=\Re\left\{\sum_{k=1}^{n} I_{k}^{*}\left(\sum_{j=1}^{n} R_{k j} I_{j}\right)\right\}
$$

System losses obtained from matrix $R$ can be decomposed in $n$ parts of losses that represent the losses attributed to each bus. Therefore, for each bus:

$$
L_{k}=\Re\left\{I_{k}^{*}\left(\sum_{j=1}^{n} R_{k j} I_{j}\right)\right\}
$$

Observing (18) one can notice that the losses components $\left(L_{k}\right)$ represent the coupling between the current injections in the $n$ buses of the system and the current injection in bus $k$.

It should be remarked that matrix Ybus, in distribution systems, is generally singular since capacitive lines effects are not considered. Moreover, in transmission system, loss allocation considers the slack bus due to its interaction with the whole network where exist different owners for the generation and transmission, and different consumers; nevertheless, in distribution systems loss allocation in the slack bus is not necessary since it is part of the utility, who is owner of the whole network. Hence, in order to obtain the loss allocation through matrix Ybus, contribution of slack bus (root node) should be neglected. This consideration does not affect neither the fair loss allocation nor the computation of system total losses, since the objective of this method is to attribute to each bus the responsibility for the payment of the losses it generates.

Another prove of the fair loss allocation is when no responsibility is given to a bus that does not present neither load nor generation. An advantage of the Zbus method is the possibility of negative loss allocation. This indicates the 
contribution that power injection caused in the system, giving "incentives" for well-positioned distributed generators or consumers. In the other hand, ill-positioned distributed generators or loads will obtain greater loss allocation.

\section{TEST Distribution NETWORK}

Analyzed distribution system presents 3 feeders and 16 buses [6]. Single-line diagram created by the graphic simulator is shown in Fig. 4. System data is presented in Table I. Distributed generator (modeled as constant power factor) data, inserted in bus 9, is presented in Table II. It can be noticed that the penetration of the distributed generation is about $25 \%$ (system demand fed by the distributed generator). Though this value may be considered as high, it was selected in order to analyze the impacts in a limit condition scenario. Low power factor (0.99) takes into account a regular distributed generator owners procedure, which is to have a power factor close to unity. Moreover, distributed generator location was chosen based on the load concentration of the bus 9 neighborhood.

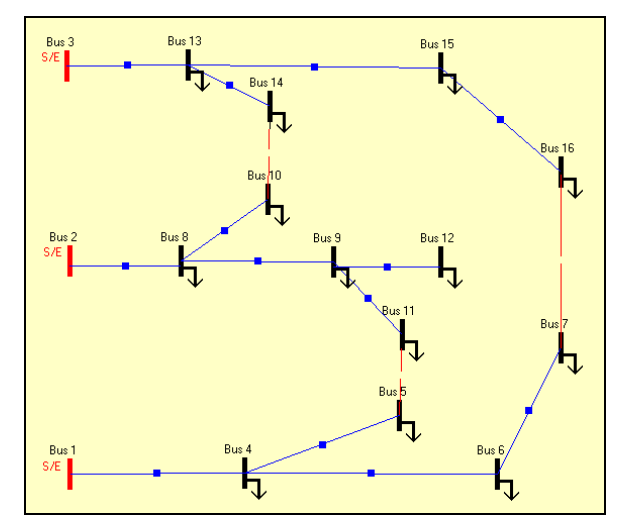

Fig. 4. Initial configuration of the system with 3 feeders.

TABLE I

16-BUS SYSTEM DATA (INITIAL CONFIGURATION)

\begin{tabular}{|c|c|c|c|c|c|c|}
\hline \multirow{2}{*}{$\begin{array}{c}\text { Initial } \\
\text { Bus }\end{array}$} & \multirow[b]{2}{*}{ End Bus } & \multicolumn{2}{|c|}{ Line } & \multicolumn{2}{|c|}{ End Bus Load } & \multirow{2}{*}{$\begin{array}{c}\text { End Bus } \\
\text { Capacitor } \\
\text { (MVAr) }\end{array}$} \\
\hline & & $\begin{array}{c}\mathbf{R} \\
\text { (p.u.) }\end{array}$ & $\begin{array}{c}X \\
\text { (p.u.) }\end{array}$ & $\begin{array}{c}\mathbf{P} \\
(\mathbf{M W})\end{array}$ & $\begin{array}{c}\mathbf{Q} \\
\text { (MVAr) }\end{array}$ & \\
\hline 1 & 4 & 0.075 & 0.1 & 2.0 & 1.6 & - \\
\hline 4 & 5 & 0.08 & 0.11 & 3.0 & 1.5 & 1.1 \\
\hline 4 & 6 & 0.09 & 0.18 & 2.0 & 0.8 & 1.2 \\
\hline 6 & 7 & 0.04 & 0.04 & 1.5 & 1.2 & - \\
\hline 2 & 8 & 0.11 & 0.11 & 4.0 & 2.7 & - \\
\hline 8 & 9 & 0.08 & 0.11 & 5.0 & 3.0 & 1.2 \\
\hline 8 & 10 & 0.11 & 0.11 & 1.0 & 0.9 & - \\
\hline 9 & 11 & 0.11 & 0.11 & 0.6 & 0.1 & 0.6 \\
\hline 9 & 12 & 0.08 & 0.11 & 4.5 & 2.0 & 3.7 \\
\hline 3 & 13 & 0.11 & 0.11 & 1.0 & 0.9 & - \\
\hline 13 & 14 & 0.09 & 0.12 & 1.0 & 0.7 & 1.8 \\
\hline 13 & 15 & 0.08 & 0.11 & 1.0 & 0.9 & - \\
\hline 15 & 16 & 0.04 & 0.04 & 2.1 & 1.0 & 1.8 \\
\hline $5 *$ & 11 & 0.04 & 0.04 & - & - & - \\
\hline $10 *$ & 14 & 0.04 & 0.04 & - & - & - \\
\hline 7* & 16 & 0.09 & 0.12 & - & - & - \\
\hline & & & Total & 28.7 & $\begin{array}{l}17.3 \\
\end{array}$ & 11.4 \\
\hline
\end{tabular}

*Initial buses of those lines that have the sectionalizing switches opened.
TABLE II

DISTRIBUTED GENERATOR DATA

\begin{tabular}{c|c|c}
\hline Bus & $\begin{array}{c}\text { Real Power } \\
\text { (MW) }\end{array}$ & $\begin{array}{c}\text { Reactive Power } \\
\text { (MVAr) }\end{array}$ \\
\hline 9 & 7.0 & 0.2 \\
\hline
\end{tabular}

\section{RESULTS}

Fig. 5 shows the main and bus properties windows of the developed graphic simulator.

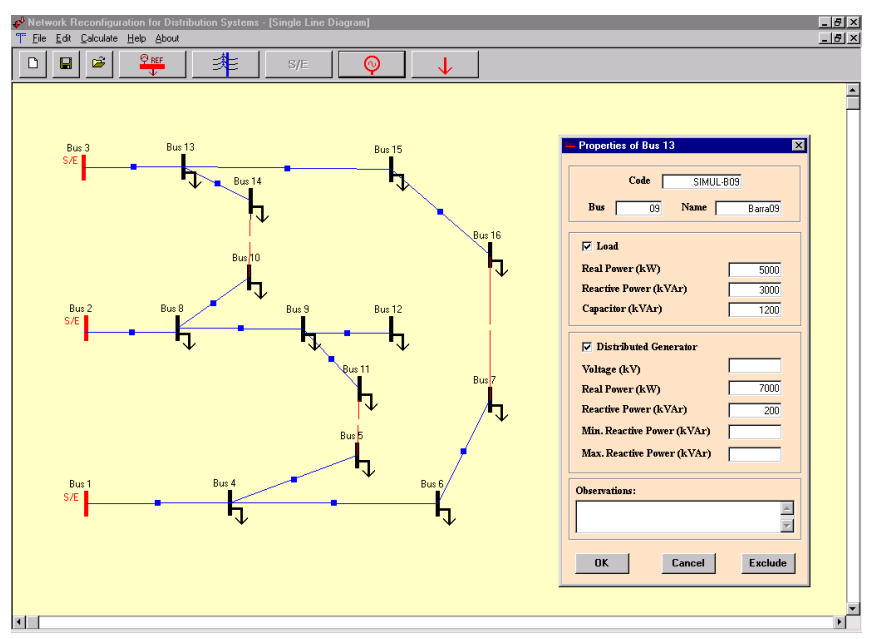

Fig. 5. Main and Bus Properties windows of the graphic simulator.

Developed graphic simulator offers 5 configurations with the smaller losses for the analyzed distribution system. Voltage levels and loss allocation for each bus are presented as attached results for each obtained configuration. Table III presents the obtained 5 configurations and their respective losses, with and without distributed generation (located at bus 9).

TABLE III

BEST CONFIGURATIONS FOR THE ANALYZED SYSTEM

\begin{tabular}{c|c|c|c|c}
\hline \multirow{2}{*}{ Config. } & \multicolumn{2}{|c|}{ without Distributed Generation } & \multicolumn{2}{c}{ with Distributed Generation } \\
\cline { 2 - 5 } & Open Switches & Loss (kW) & Open Switches & Loss (kW) \\
\hline $\mathbf{1}$ & $9-11 / 8-10 / 7-16$ & 485.48 & $5-11 / 8-10 / 7-16$ & 262.43 \\
\hline $\mathbf{2}$ & $5-11 / 8-10 / 7-16$ & 499.59 & $9-11 / 8-10 / 7-16$ & 264.28 \\
\hline $\mathbf{3}$ & $9-11 / 10-14 / 7-16$ & 502.80 & $5-11 / 10-14 / 7-16^{*}$ & 264.69 \\
\hline $\mathbf{4}$ & $9-11 / 8-10 / 6-7$ & 513.50 & $9-11 / 10-14 / 7-16$ & 266.20 \\
\hline $\mathbf{5}$ & $5-11 / 10-14 / 7-16^{*}$ & 517.25 & $9-11 / 13-14 / 7-16$ & 276.45 \\
\hline
\end{tabular}

*Initial system configuration.

It is noticed a considerable decrease in the loss values when the distributed generator is inserted. Moreover, obtained configurations in both cases are not the same. Distributed generation, from the perspective of losses, impacted positively in the analyzed distribution network, achieving values of losses about $45 \%$ of those configurations without distributed generation. It is observed that initial configuration, with and without distributed generation, appears in Table III, which indicates that is a good quality configuration.

Table IV presents the voltage levels and loss allocation for the initial configuration of the 16-bus system, with and without distributed generator (located in bus 9). 
TABLE IV

Voltage LeVEls AND Loss ALLOCATION FOR EACH Bus

\begin{tabular}{|c|c|c|c|c|}
\hline \multirow[b]{2}{*}{ Bus } & \multicolumn{2}{|c|}{ Voltage Levels (p.u.) } & \multicolumn{2}{|c|}{ Loss Allocation (kW) } \\
\hline & $\begin{array}{c}\text { Without } \\
\text { Generation }\end{array}$ & $\begin{array}{c}\text { With } \\
\text { Generation }\end{array}$ & $\begin{array}{c}\text { Without } \\
\text { Generation }\end{array}$ & $\begin{array}{c}\text { With } \\
\text { Generation }\end{array}$ \\
\hline 1 & 1.0000 & 1.0000 & 0.00 & 0.00 \\
\hline 2 & 1.0000 & 1.0000 & 0.00 & 0.00 \\
\hline 3 & 1.0000 & 1.0000 & 0.00 & 0.00 \\
\hline 4 & 0.9965 & 0.9965 & 16.11 & 16.11 \\
\hline 5 & 0.9946 & 0.9946 & 27.29 & 27.29 \\
\hline 6 & 0.9949 & 0.9949 & 17.92 & 17.92 \\
\hline 7 & 0.9939 & 0.9939 & 32.43 & 32.43 \\
\hline 8 & 0.9871 & 0.9947 & 75.94 & 45.14 \\
\hline 9 & 0.9789 & 0.9918 & 129.21 & -17.02 \\
\hline 10 & 0.9871 & 0.9946 & 21.77 & 14.07 \\
\hline 11 & 0.9777 & 0.9906 & 13.89 & 5.91 \\
\hline 12 & 0.9735 & 0.9864 & 124.18 & 64.33 \\
\hline 13 & 0.9943 & 0.9943 & 5.51 & 5.51 \\
\hline 14 & 0.9920 & 0.9920 & 7.72 & 7.72 \\
\hline 15 & 0.9920 & 0.9920 & 8.06 & 8.06 \\
\hline 16 & 0.9804 & 0.9804 & 37.21 & 37.21 \\
\hline & & Total & 517.25 & 264.69 \\
\hline
\end{tabular}

It can be observed that method Zbus does not allocate losses to the slack buses. In general, loss allocation diminished for those buses near the distributed generator. Moreover, bus 9 received negative loss allocation, which means method Zbus recognized the positive impact of that power injection. Furthermore, it is verified that total allocated losses (Table IV) and total losses (Table III) for both configurations, with and without distributed generation, are equal. This fact proves the reliability of the Zbus method results.

Another aspect that can be analyzed, in order to evaluate the distributed generation impact, is the voltage profile. Fig. 6 shows the voltage profile of the analyzed system for the sections of feeder 2, where the distributed generator was inserted. Since, voltage drop and power losses are related, it can be verified that the presence of the distributed generation, at bus 9 , improve positively the voltage profile, improving power supply quality indices.

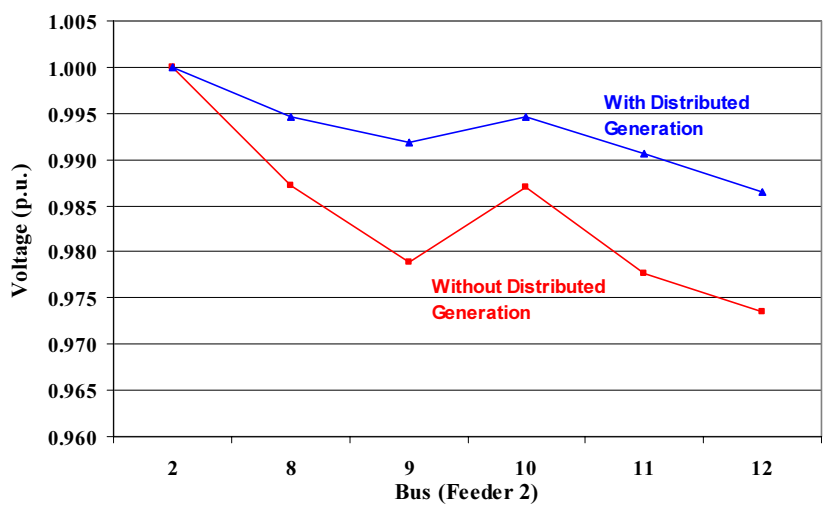

Fig. 6. Voltage levels in the feeder 2 with and without distributed generation.

\section{CONCLUSIONS}

Nowadays, structural changes in distribution networks are intensive due to the loads connection or disconnection, as well as the insertion of distributed generation. Presented graphic simulator contributes for a faster response in the results analysis, remarking the easiness to input data because of the friendly interface which allows the user to create graphically the system to be analyzed, and perform changes at any time with no major problems.

Utilized power flow algorithm, based on the backwardforward technique, was robust and efficient considering the presence of distributed generation.

Though the heuristic methodology used for network reconfiguration considered mainly the criterion of maximum voltage drop, other technical aspects can be included.

Zbus method presented good performance solving the loss allocation problem, obtaining coherent and fair results.

Combination of network reconfiguration and loss allocation is a good tool for analysis of distributed generation allocation, since the impact on system losses and its economical benefits for consumers and generators owners, are considered together.

\section{REFERENCES}

[1] J. R. S. Mantovani, F. Casari, and R. A. Romero, "Reconfiguração de sistemas de distribuição radiais utilizando o critério de queda de tensão," in SBA Controle \& Automação, vol. 11, no. 3, pp. 150-159, Set. 2000.

[2] N. Kagan and C. C. B. Oliveira, "Reconfiguração de redes de distribuição de energia elétrica através de ferramenta para solução de problemas de decisão com múltiplos objetivos e incertezas," in $S B A$ Controle \& Automação, vol. 9, no. 1, pp. 18-30, 1998.

[3] D. Shirmohammadi, H. W. Hong, A. Semlyen, and G. X. Luo, "A compensation-based power flow method for weakly meshed distribution and transmission networks," IEEE Trans. on Power Systems, vol. 3, no. 2, pp. 753-762, May 1988.

[4] I. F. E. D., Denis, R. M. Ciric, and A. Padilha, "Métodos de alocação de perdas em sistemas de distribuição com geradores distribuídos," in Proc. 2002 Congresso Brasileiro de Automática, pp. 849-854.

[5] A. J. Conejo, F. D. Galiana, and I. Kockar, "Z-buss loss allocation," IEEE Trans. On Power Systems, vol. 16, no. 1, pp. 105-110, Feb. 2001.

[6] S. Cinvalar, J. J. Grainger, and H. Yin, S. S. H. Lee, "Distribution feeder reconfiguration for loss reduction," IEEE Trans. on Power Delivery, vol. 3, no. 3, pp. 1217-1223, July 1988.

\section{BIOGRAPHIES}

Marcelo Escobar de Oliveira electrical engineering student from UNESP - Ilha Solteira, SP, Brazil. His research interests are distribution system analysis and distributed generation.

Luis Fernando Ochoa (S'01) graduated from the National Engineering University (U.N.I.) - Lima, Peru, in 2000. He obtained the M.Sc. degree from UNESP - Ilha Solteira, SP, Brazil in 2003. Currently he is towards the Ph.D. at UNESP - Ilha Solteira, SP, Brazil. His research interests are distribution system analysis and distributed generation.

Antonio Padilha Feltrin (M'89) obtained the B.Sc. degree from EFEI, the M.Sc. and Ph.D. from UNICAMP, Brazil. He is currently an Associate Professor of Electrical Engineering Department of UNESP - Ilha Solteira, SP, Brazil. From 1995 to 1997 he was a Visiting Faculty at ECE Department of University of Wisconsin - Madison. His main interests are in analysis and control of power systems.

José Roberto Sanches Mantovani he received his B.Sc. degree in 1981 from UNESP - Ilha Solteira, SP, Brazil, and the Doctor's degree in Electrical Engineering in 1995 from UNICAMP, Campinas, SP, Brazil. Currently he is Associate Professor of Electrical Engineering Department of UNESP - Ilha Solteira, SP, Brazil. His general research interest is in electric power systems planning and control areas. 